\title{
Association of socio-demographic issues with level of knowledge of HIVIAIDS among injecting drug users in Dhaka City in Bangladesh
}

\author{
Nasreen Nahar ${ }^{1}$, Jesmin Akter ${ }^{2}$, Md. Shahriar Mahbub ${ }^{3}$, Rabeya Sultana ${ }^{4}$, Farzana Islam Khan ${ }^{5}$, \\ Mithila Faruque 6 , Begum Rowshan Ara
}

${ }^{1}$ Assistant Professor, ${ }^{2,4,5,6}$ Lecturer, ${ }^{7}$ Professor and Head, Department of Reproductive and Child Health; ${ }^{3}$ Student, Masters in Public Health, Department of Non-communicable Diseases; Bangladesh University of Health Sciences (BUHS), Mirpur, Dhaka, Bangladesh.

\begin{abstract}
Human Immune Deficiency Virus (HIV) and Acquired immune Deficiency Syndromes (AIDS) continues to be a major burden of morbidity and mortality among the population. Injecting drug users (IDUs) are at high risk of contracting the disease. The study was conducted to assess the level of knowledge of HIV/AIDS and the influence of different socio-demographic factors among IDUs in Dhaka city, Bangladesh. A descriptive type of cross-sectional study was conducted. A total of 200 injecting drug users were selected purposively. A semi-structured questionnaire was used for collecting socio-demographic information of the respondents and their knowledge regarding HIV/AIDS. The level of knowledge was categorized into two: poor $(<$ Mean $-1 \mathrm{SD})$ and good $(\geq \mathrm{Mean}+1 \mathrm{SD})$. The $\chi 2$ test was used for finding the association between socio-demographic factors and level of knowledge about HIV/AIDS. Fortyeight percent of the respondents were aged 18-26 years, and 33\% were educated up to secondary level. About $47 \%$ had an income of Taka 4500-5500. Of the respondents, $41 \%$ and $47 \%$ were aware of HIV/AIDS and their preventive measures respectively. Age and education of the respondents were significantly $(\mathrm{p}<0.05)$ associated with level of knowledge of HIV/AIDS among IDUs. Functional and productive educational campaigns to educate people regarding the health consequences of HIV/AIDS are strongly suggested for creating awareness through disseminating knowledge among IDUs in Bangladesh particularly for the age group with a low level of knowledge and limited access to HIV/AIDS educational intervention programs.
\end{abstract}

Keywords: Socio-demographic factors, Knowledge, IDU, HIV/AIDS, Bangladesh.

\section{Introduction}

HIV/AIDS is a major source of morbidity and mortality worldwide with a large socioeconomic impact. In 2015, an estimated five million people were living with HIV in South, South-East, and East Asia combined. ${ }^{1}$ Five countries (India, Indonesia, Myanmar, Nepal, and Thailand) account for the majority of HIV infections in the same region. ${ }^{2}$ Among the countries of the South Asian Association for Regional Cooperation (SAARC), India has the highest prevalence of HIV/AIDS.

Bangladesh is at vulnerable location for spread of HIV/ AIDS due to its geographical proximity with India. ${ }^{3}$ The cumulative number of reported HIV cases in Bangladesh in 2015 stood at 3,674, AIDS cases at 1,101, and death toll at $325 .{ }^{4,5}$ However, the actual number of HIV/AIDS cases is still unknown due to limited and incomplete surveillance facilities. ${ }^{6}$

Among the drug-related infectious diseases, HIV/AIDS carries the most serious health consequences. Explosive HIV epidemics have occurred in many countries among injecting drug-users (IDUs), most recently in Asia, where risky injection practices have been attributed to rapid HIV spread. $^{7}$ This issue has become more complex by an overlap of sex and drug networks of IDUs, which may not only enhance their vulnerability to HIV but can also promote HIV transmission among their sexual partners. ${ }^{8}$

\section{Practice Points}

- HIV/AIDS is considered to be an epidemic when $10 \%$ of the total population is affected. Recently, Bangladesh had a concentrated HIV epidemic among IDUs.

- Explosive HIV epidemics among IDUs have become more complex by an overlap of sex and drug networks of IDUs, which may not only enhance their vulnerability to HIV but can also promote HIV transmission among their sexual partners.

- An important factor for spreading the disease is through selling infected blood by IDUs for buying drugs.

- Most IDUs represent socio-economically diverse population groups. Lack of knowledge about safe sex, contraceptive methods, STIs, and HIV infection can be attributed to a low literacy rate among IDUs.

- The IDUs are less likely to access health care services due to fear of discrimination and social stigma. Thus it is important to develop and implement effective harm-reduction strategies for IDUs.

Correspondence: Dr. Nasreen Nahar, Assistant Professor, Department of Reproductive and Child Health, Bangladesh University of Health Sciences (BUHS), 125/1, Darus Salam, Mirpur, Dhaka-1216, Bangladesh. E-mail: drnasreennahar@yahoo.com. 
Worldwide around 16 million people are IDUs and of these around 3 million are infected with HIV. ${ }^{9}$ It is estimated that around $10 \%$ of new HIV infection is due to injecting drug use. ${ }^{9}$ Like other developing countries, drug-use has been increasing in both urban and rural communities in Bangladesh. ${ }^{10}$ The estimated number of IDUs was at least 20,000-40,000 in 2008 in Bangladesh, of which at least 5,000 were concentrated in Dhaka itself. 4,11

A significant number of IDUs are extremely marginalized and live on the streets and out of any social structure, which leave them in a more vulnerable situation. Recently, Bangladesh had a concentrated HIV epidemic among IDUs. ${ }^{12}$ The latest round (2011) of serological surveillance in Bangladesh showed that the prevalence of HIV was less than $1 \%$ among all population group tested, with the exception of IDUs.

The prevalence of HIV in the cluster of IDUs increased from $4 \%$ in 2002 to $7 \%$ (in one locality of central Dhaka) in 2007-2008, which fell to $5.3 \%$ in $2010 .^{11}$ HIV/AIDS is considered to be an epidemic when $10 \%$ of the total population is affected. But when $5 \%$ among the high-risk group of population (such as IDUs, commercial sex workers, men who have sex with men, truck drivers) is affected by HIV/AIDS, it is considered to be an epidemic condition. ${ }^{12}$ The IDUs often engage in unsafe sexual behavior which increases their risks of acquiring sexually transmitted infections (STIs) and HIV infection. ${ }^{13}$

Drug-users are mobile as they travel from one city to another. This enhances the possibility of contracting the disease. They contribute to the spread of infection by needle-sharing among themselves and also through sexual contact with commercial sex workers. An additional issue of concern is the bridging effect whereby non-injecting population is at risk of acquiring HIV/AIDS through sexual contact with IDUs. Another important factor for spreading the disease is through selling infected blood by IDUs for buying drugs. ${ }^{13}$

HIV/AIDS and IDUs both pose a significant challenge to sustainable human development in several regions of the world. $^{14}$ Economic, political and social changes make the situation more difficult and increase vulnerability to HIV infection. ${ }^{14}$ Most IDUs represent socio-economically diverse population groups. ${ }^{15}$ Lack of knowledge about safe sex, contraceptive methods, STIs, and HIV infection can be attributed to a low literacy rate among IDUs. ${ }^{12}$

HIV/AIDS continues to be a neglected issue among IDUs. There is a paucity of data regarding level of knowledge of HIV/AIDS among IDUs in Bangladesh. It is important to explore the level of knowledge among IDUs on HIV/AIDS infection including its mode of transmission, prevention and treatment among others. It is also prudent to investigate the influence of the different social, demographic and economic factors that contribute to the spread of HIV among IDUs.

This study is aimed to identify those sections of IDUs who need greater attention from intervention programs for promoting harm reduction from HIV.

\section{Materials and methods}

Study Design and Study Area

This cross-sectional descriptive study was conducted in 2013 among IDUs in Shahzadpur, Uttara, Dhaka to assess the level of their knowledge of HIV/AIDS and the influence of different socio-demographic factors on their knowledge level.

\section{Study population}

A total of 200 eligible consecutive respondents were selected through purposive sampling. The respondents were identified with the help of field supervisor of a drop-in center (DIC) working with IDUs at the study area. The rationale behind purposive sampling was an unwillingness of self-identification as IDUs due to social stigma. Those who were unwilling to participate in the study were excluded.

\section{Data Collection}

Data were collected by face-to-face interview method using a set of semi-structured questionnaires adapted from the WHO's Modified AIDS Questionnaire. ${ }^{16} \mathrm{~A}$ brief introduction explaining the importance of the study was given verbally to each respondent at the beginning of the interview. Data were collected by trained interviewers who had a minimum of secondary level education. An orientation about the questionnaires and instructions about their applications was conducted among interviewers prior to commencement of the actual data gathering procedure. The questionnaire was used for collecting socio-demographic information of the respondents and their knowledge regarding HIV/ AIDS.

The English questionnaire was translated into Bangla. The Bangla version of questionnaire was pretested to assess its clarity, sequencing, and time needed to complete it. It was modified based on the results of pretesting.

\section{Ethical aspects}

The Ethical Review Committee of Bangladesh University of Health Sciences (BUHS) approved the study. Written informed consent was obtained from all the participants. Ethics has been respected throughout the study period. No data was disclosed without the permission of the respondents. No forceful attempt was taken to interview any unwilling respondent. Respondent's right to refuse and withdraw from the study anytime was respected.

\section{Scoring}

The questionnaire included 18 questions relating to level of knowledge of HIV/AIDS, with 54 probable answers. Each correct answer scored 1, and the wrong or unknown answer scored 0 . The level of knowledge was divided into two categories - poor, and good. Poor knowledge corresponded to a score of $(<$ Mean $-1 \mathrm{SD})$; good knowledge corresponded to a score of $(\geq$ Mean +1 SD). ${ }^{17}$

\section{Analysis of Data}

The Window-based computer software, devised with the Statistical Packages for Social Sciences (SPSSC) 17.0, SPSS Inc., Chicago, IL, USA), was used for analyzing data. Descriptive statistics was used for the interpretation of the findings. Frequency distribution for 
all the variables was worked out and produced in a tabular form. The $\chi 2$ test was used for finding the association between the socio-demographic factors and the level of knowledge of the respondents. A two-tailed $p$ value of $<0.05$ was considered significant at $95 \%$ confidence interval (CI) level.

\section{Results}

In total, 200 respondents were involved in the study. Of them, $48 \%$ were aged $18-26$ years, and about $68 \%$ were married. About $28 \%$ of the respondents were illiterate; $25 \%$ were educated up to tenth grade level; $26 \%$ could read and write; and $22 \%$ could read only. Fifty-six percent of the respondent-fathers were illiterate, and only $6.5 \%$ were educated up to tenth grade level. About $35 \%$ of the respondent-fathers were farmers, and $32 \%$ were shopkeepers (Table 1).

Of the respondents, $60 \%$ were living in family residence and the rest $40 \%$ were living in other types of accommodation. About $47 \%$ of the respondents had a monthly family income of Taka 4,500-5,500, and 41\% had a family income of less than Taka 6,500 (Table 1).

Table 2 describes knowledge about HIV/AIDS among IDUs and the responses were categorized as 'correct' and 'incorrect'. Of the respondents, $41 \%$ were aware of or had knowledge on HIV/AIDS, and $49 \%$ were aware of the causative agent of AIDS. About $56 \%$ had good level of knowledge of AIDS as an infectious disease,

Table 1: Sociodemographic characteristics of respondents $(n=200)$

\begin{tabular}{|c|c|}
\hline Characteristics & Respondents (\%) \\
\hline \multicolumn{2}{|l|}{ Age (years) } \\
\hline $18-26$ & $96(48 \%)$ \\
\hline $27-35$ & $67(33.5 \%)$ \\
\hline $36-44$ & $19(9.5 \%)$ \\
\hline $45-53+$ & $18(9 \%)$ \\
\hline \multicolumn{2}{|l|}{ Marital status } \\
\hline Married & $135(67.5 \%)$ \\
\hline Unmarried & $58(29 \%)$ \\
\hline Divorced & $7(3.5 \%)$ \\
\hline \multicolumn{2}{|c|}{ Education of respondents } \\
\hline Illiterate & $55(27.5 \%)$ \\
\hline Only reading & $44(22 \%)$ \\
\hline Reading and writing & $51(25.5 \%)$ \\
\hline Fifth to tenth grade & $50(25 \%)$ \\
\hline \multicolumn{2}{|l|}{ Education of fathers } \\
\hline Illiterate & $112(56 \%)$ \\
\hline Only reading & $11(5.5 \%)$ \\
\hline Reading and writing & $64(32 \%)$ \\
\hline Fifth to tenth grade & $13(6.5 \%)$ \\
\hline \multicolumn{2}{|l|}{ Occupation of fathers } \\
\hline Farmer & $70(35 \%)$ \\
\hline Unemployed & $24(12 \%)$ \\
\hline Shopkeeper & $64(32 \%)$ \\
\hline Others & $42(21 \%)$ \\
\hline \multicolumn{2}{|l|}{ Place of residence } \\
\hline Living with family & $120(60 \%)$ \\
\hline Living with others & $80(40 \%)$ \\
\hline \multicolumn{2}{|c|}{ Monthly family income (Taka) } \\
\hline $4,500-5,500$ & $93(46.5 \%)$ \\
\hline $5,501-6,500$ & $82(41 \%)$ \\
\hline $6,501+$ & $25(12.5 \%)$ \\
\hline
\end{tabular}

and $34.5 \%$ had some knowledge on the mode of transmission of HIV/AIDS. About $48 \%$ knew about AIDS as a serious disease. About $60 \%$ were not aware that HIV could be transmitted through mosquito bites, and $23 \%$ were aware that it could not be transmitted during bathing and sharing of bed and clothes.

Of the respondents, $68 \%$ and $57 \%$ had good level of knowledge of treatment and AIDS vaccine respectively. About $57 \%$ and $77 \%$ had no idea about the risk factors and consequence of HIV/AIDS respectively. Forty-five percent were aware of the high risk groups of HIV/AIDS transmission, and $39.5 \%$ had good knowledge about condom to prevent HIV/AIDS.

Less than half $(42.5 \%)$ of the respondents had concerns about available services relating to HIV/ AIDS, and 55\% had poor knowledge on morality due to HIV/AIDS. Of the respondents, $47 \%$ were aware of the preventative measures of HIV/AIDS, and $61 \%$ were familiar with the screening test for HIV. About $62 \%$ had no knowledge on the available source of information on HIV/AIDS (Table 2).

Table 3 shows the evidence of significant relationships between a set of socio-demographic factors and IDUs' level of knowledge of HIV/AIDS. The respondents aged 18-26 years had better level of knowledge compared to those aged 45-53 years $(p<0.05)$. Level of knowledge was better among more educated respondents (fifth grade to tenth grade) compared to the illiterate respondents $(p<0.05)$. However, monthly family income and place of residence had no significant relationship with the level of knowledge $(\mathrm{p}>0.05)$ (Table 3$)$.

\section{Discussion}

The prevalence of HIV in Bangladesh remains relatively at a low level. ${ }^{6}$ The spread of HIV among the risk groups is increasing. The use of injecting drugs is an alarming problem in Bangladesh. ${ }^{11}$ The IDUs present a significant potential for an HIV epidemic due to their needle-sharing habits and through unsafe sex with commercial sex workers. ${ }^{9}$ The IDUs are relatively neglected and represent a diverse section of the society with regard to access to health information and health services. The present study was designed to understand the association between socio-demographic factors and the level of knowledge of HIV/AIDS among IDUs.

This study shows that most IDUs belong to the age-group of 18-26 years. Young age is a vulnerable period when they are exposed to new experiences relating to sexuality and reproduction. ${ }^{18}$ This finding is similar to those found in the studies conducted in Iran and Bangladesh. ${ }^{19-21}$ Most of our participants had secondary school education (fifth grade to tenth grade) and all were unemployed.

The present study revealed that $41 \%$ of the respondents had knowledge on HIV/AIDS. This finding is higher than that of the study conducted among Afghani and Pakistani drug-users in Quetta, Pakistan. ${ }^{22}$ It may be due to the fact that the education system in those countries has been affected by two 
Nahar et al. Association of socio-demographic characteristics and level of knowledge of HIV/AIDS

Table 2: Respondents' level of knowledge of HIV/AIDS ( $n=200)$

\begin{tabular}{|l|c|c|}
\hline Knowledge items* & Correct Response (\%) & Incorrect Response (\%) \\
\hline Ever-heard of HIV/AIDS & $82(41 \%)$ & $118(59 \%)$ \\
\hline Causative agent of AIDS & $98(49 \%)$ & $102(47 \%)$ \\
\hline AIDS is an infectious disease & $111(55 \%)$ & $131(65.5 \%)$ \\
\hline Mode of transmission of HIV/AIDS & $69(34.5 \%)$ & $95(47.5 \%)$ \\
\hline $\begin{array}{l}\text { AIDS is not a serious disease. It is a simple disease like } \\
\text { the common cold }\end{array}$ & $105(52.5 \%)$ & $119(59.5 \%)$ \\
\hline Mosquito bite and HIV transmission & $81(40.5 \%)$ & $154(77 \%)$ \\
\hline Bathing, sharing bed and cloth and HIV transmission & $46(23 \%)$ & $64(32 \%)$ \\
\hline Treatment of AIDS & $136(68 \%)$ & $114(57 \%)$ \\
\hline Vaccine of AIDS & $114(57 \%)$ & $121(76.5 \%)$ \\
\hline Risk factors of HIV/AIDS & $86(43 \%)$ & $110(55 \%)$ \\
\hline Consequences of HIV/AIDS & $79(39.5 \%)$ & $112(56 \%)$ \\
\hline High-risk groups of HIV/AIDS transmission & $90(45 \%)$ & $115(57.5 \%)$ \\
\hline $\begin{array}{l}\text { Knowledge about contraceptive method (e.g. condom) } \\
\text { of preventing AIDS }\end{array}$ & $79(39.5 \%)$ & $110(55 \%)$ \\
\hline Service available for health education about HIV/AIDS & $85(42.5 \%)$ & $106(53 \%)$ \\
\hline Mortality due to HIV/AIDS & $90(45 \%)$ & $78(39 \%)$ \\
\hline Prevention of AIDS & $94(47 \%)$ & $123(61.5 \%)$ \\
\hline Screening test for HIV & $122(61 \%)$ & $77(38.5 \%)$ \\
\hline Available source of information on HIV/AIDS & & \\
\hline
\end{tabular}

Table 3: Association between respondents' level of knowledge and socio-demographic variables $(n=200)$

\begin{tabular}{|c|c|c|c|}
\hline \multirow{2}{*}{ Variables } & \multicolumn{2}{|c|}{ Knowledge } & \multirow{2}{*}{ p-value } \\
\hline & Good Knowledge (\%) & Poor Knowledge (\%) & \\
\hline \multicolumn{4}{|l|}{ Age in years } \\
\hline $18-26$ & $44(22 \%)$ & $52(26 \%)$ & \multirow{4}{*}{0.022} \\
\hline $27-35$ & $25(12.5 \%)$ & $42(21 \%)$ & \\
\hline $36-44$ & $7(3.5 \%)$ & $12(6 \%)$ & \\
\hline $45-53+$ & $7(3.5 \%)$ & $11(5.5 \%)$ & \\
\hline \multicolumn{4}{|l|}{ Education of respondents } \\
\hline Illiterate & $14(7 \%)$ & $41(20.5 \%)$ & \multirow{4}{*}{0.006} \\
\hline Only reading & $6(3 \%)$ & $15(7.5 \%)$ & \\
\hline Reading and writing & $24(12 \%)$ & $34(17 \%)$ & \\
\hline Fifth grade to tenth grade & $39(19.5 \%)$ & $27(13.5 \%)$ & \\
\hline \multicolumn{4}{|l|}{ Occupation of father } \\
\hline Farmer & $27(13.5 \%)$ & $43(21.5 \%)$ & \multirow{4}{*}{0.187} \\
\hline Shopkeeper & $14(7 \%)$ & $10(5 \%)$ & \\
\hline Unemployed & $25(12.5 \%)$ & $39(19.5 \%)$ & \\
\hline Others & $22(11 \%)$ & $20(10 \%)$ & \\
\hline \multicolumn{4}{|l|}{ Place of residence } \\
\hline Living with family & $56(28 \%)$ & $64(32 \%)$ & \multirow{2}{*}{0.018} \\
\hline Living with others & $33(16.5 \%)$ & $47(23.5 \%)$ & \\
\hline \multicolumn{4}{|c|}{ Monthly family income (BDT) } \\
\hline $4500-5500$ & $38(19 \%)$ & $55(27.5 \%)$ & \multirow{3}{*}{0.085} \\
\hline $5501-6500$ & $42(21 \%)$ & $40(20 \%)$ & \\
\hline $6500+$ & $10(5 \%)$ & $15(7.5 \%)$ & \\
\hline
\end{tabular}

*The level of significance at $\alpha=0.05$

decades of war and political turmoil.

Only $34.5 \%$ of the study participants were aware of the mode of transmission of HIV/AIDS. The lower percentage of our study differs from the finding of a previous study in Bangladesh which was conducted among drug-users using different routes including IDUs. ${ }^{20}$ About $60 \%$ of the respondents believed that HIV could be transmitted through the mosquito bite. This finding is fairly similar to the findings of studies in Rio de
Janeiro, Brazil, and Kabul, Afghanistan..$^{23,24}$ It appears that a major gap in knowledge exists among drug-users about the means of transmitting/ acquiring HIV. Correct response about treatment of HIV/AIDS (68\%) was considerably higher among our study participants compared to the findings of the study in Vietnam on most-at-risk populations. ${ }^{25}$

Only $39.5 \%$ of the study respondents thought that the use of condom could prevent HIV/AIDS. This

South East Asia Journal of Public Health 2017;7(1):42-47 
was found to be higher in a study among drug-users in Brazil. $^{23}$ One possible reason for the difference between the findings of the two studies could be that the Brazilian study was conducted among all types of drugusers whereas our study included only IDUs. Another possible explanation is the lower educational level of our interviewees. Of the study respondents, $47 \%$ were aware of the preventive measures of HIV/AIDS. This is in contrast to a study conducted by the World Bank which showed that only $17 \%$ of the most at-risk population had correct knowledge of prevention of HIV/ AIDS. ${ }^{15}$ The time elapsed since conduction of the World Bank study (2001) and the present one might have resulted in higher percentage of level of knowledge about preventive measures of HIV/AIDS.

This study showed that level of knowledge of HIV/ AIDS was significantly associated with the age of the respondents. The respondents aged 18-26 years were relatively better aware of HIV/AIDS compared to those aged 45-53 years. Poor level of knowledge in the latter group may be related to the traditional social system and healthcare service which often pay less attention to this group of people. A separate study in Bangladesh reported similar findings. ${ }^{26}$

Literacy has a positive impact on improving level of knowledge. ${ }^{27}$ It affected the level of knowledge of HIV/ AIDS in our study as well as other studies done elsewhere. $^{26,27}$ This can be explained by the fact that educated people can acquire more knowledge when they are exposed to sources of available information like electronic media (databases, Internet) and printed materials (books, journals, newspapers, posters, booklets). The highest number of the respondents was from low socio-economic background and all of them were unemployed. However, their family income, place of residence, and occupation revealed no significant relationship with their knowledge level.

Intravenous drug users belong to high-risk groups for the spread of HIV/AIDS. This study explored this important yet under-represented group among the highrisk population for knowledge regarding HIV/AIDS.

One of the limitation of this study was small sample size of two hundred respondents. A larger study would entail larger sample size which was not possible in this case due to time and fund constraints.

\section{Conclusion}

The IDUs are three times more likely to be infected with HIV through needle sharing than sexual intercourse. They are less likely to access health care services due to fear of discrimination and social stigma. Thus it is important to develop and implement effective harmreduction strategies for HIV/AIDS among high-risk groups like IDUs. There are a few ongoing harmreduction interventions in Bangladesh e.g. needle and syringe exchange program.

The present study revealed that level of knowledge of HIV/AIDS among IDUs is positively influenced by the age and level of education. Based on this it could be proposed that to raise level of knowledge of HIV/AIDS among IDUs emphasis should be given on developing appropriate educational intervention programs particularly for the age group with a low level of knowledge and those with a low access to healthcare information on HIV/AIDS.

\section{Competing interest}

The authors declare that they have no competing interests.

\section{Acknowledgement}

We thank the Bangladesh University of Health Sciences (BUHS) for giving us the opportunity to conduct the study. We are indebted to the data-collectors, respondents, and the management of the health centers for their kind cooperation. We also thank Mr. M. Shamsul Islam Khan, Advisor, Department of Library and Part-Time Faculty, English Foundation Course, BUHS for editing the paper.

\section{References}

1. The Joint United Nations Programme on HIV and AIDS (UNAIDS). Global AIDS Update. Geneva: UNAIDS, 2016.

2. World Health Organization. HIV/AIDS in the South-East Asia Region: Progress Report. New Delhi World Health Organization, Regional Office for South-East Asia, 2012.

3. Alam MK. Geographical location of Bangladesh and vulnerability to AIDS. https:// khairul.wordpress.com/tag/rainbow-nari-o-shishu -kallyan-foundation/ (accessed May 2017)

4. Ministry of Health and Family Welfare. National HIV Serological Surveillance, 2011, Bangladesh. Dhaka: Ministry of Health and Family Welfare, 2012.

5. UNAIDS. Annual Progress Report: Bangladesh. http://www.unaids.org/sites/default/files/country/ documents/BGD narrative report_2015.pdf (accessed June 2017)

6. Mondal NI, Takaku H, Ohkusa Y, Sugawara T, Okabe N. HIV/AIDS acquisition and transmission in Bangladesh: turning to the concentrated epidemic. Jpn J Infect Dis 2009;62 (2):111-9.

7. UNAIDS/WHO. AIDS epidemic update: December 2005. Geneva: UNAIDS, 2005.

8. Evans JL, Hahn JA, Page-Shafer K, Lum PJ, Stein ES, Davidson PJ, et al. Gender differences in sexual and injection risk behavior among active young injection drug users in San Francisco (the UFO Study). J Urban Health 2003;80(1):137-46.

9. UNODC. Factsheet - HIV among people who use drugs. https://www.unodc.org/documents/hiv -aids/publications/People who_use drugs/1380131 factsheet HIV drugs-Final.pdf (accessed May 2017)

10. UNODC. Bangladesh. In: South Asia Regional Profile. $\quad$ https://www.unodc.org/pdf/india/ publications/ south Asia Regional Profile Sept 2005/08 ban gladesh.pdf (accessed May 2017) 
11. Family Health International. Bangladesh Final Report, September 1997-September 2007 for USAID's Implementing AIDS Prevention and Care (IMPACT) Project. Arlington, VA, USA: Family Health International, 2007.

12. Nazrul Islam SK, Hossain KJ, Ahsan M. Sexual life style, drug habit and socio-demographic status of drug addicts in Bangladesh. Public Health 2000;114(5):389-92.

13. World Health Organization. HIV/AIDS Strategic Framework for WHO South-East Asia Region 2002-2006. http://www.who.int/hiv/strategic/ pubsear135/en/ (accessed May 2017)

14. Interagency Coalition on AIDS and Development. HIV/AIDS, Injection Drug Use, Harm Reduction and Development. www.icadcisd.com/index.php?

op-

$\underline{\underline{\text { tion }}}=\mathrm{com}$ jotloader $\&$ section $=$ files $\&$ task $=$ downlo ad\&cid=32 19a5bc7d520e72a5c573f3408916d8 78\&Itemid=260\&lang=en (accessed May 2017)

15. Medhi GK, Mahanta J, Paranjape RS, Adhikary $\mathrm{R}$, Singh SG, Akoijam S, et al. Factors associated with ever HIV testing among injecting drug users (IDUs) in two HIV high prevalent States of India. Indian J Med Res 2012;136 (Supplement):64-71.

16. World Health Organization. HIV testing, treatment and prevention: generic tools for operational research. http://www.who.int/hiv/ pub/vct/generic/en/ (accessed June 2017)

17. Priyanka Raj CK, Angadi MM. Hospital-based KAP study on diabetes in Bijapur, Karnataka. Indian J Med Special 2010:1(2):80-3.

18. Khan MA. Knowledge on AIDS among female adolescents in Bangladesh: evidence from the Bangladesh demographic and health survey data. J Health Popul Nutr 2002;20(2):130-37.

19. Ali Reza M, Abbas E, Bahram S, Ehsan M. Prevalence of Human Immunodeficiency Virus Infection among Injection Drug Users Released from Jail. Addict Health 2012;4(3-4):151-5.
20. Huq AKO, Chowdhury $\mathrm{T}$, Rana M, Alam J, Moktadir SG, Manir M. Nutritional status and KAP about HIV/AIDS among floating drug addicted and commercial sex workers in Dhaka City, Bangladesh. J AIDS HIV Res 2013;5 (9):334-40

21. Kazerooni PA, Lari MA, Joolaei H, Parsa N. Knowledge and Attitude of Male Intravenous Drug Users on HIV/AIDS Associated High Risk Behaviors in Shiraz Pir-Banon Jail, Fars Province, Southern Iran. Iranian Red Crescent Med J 2010;12(3):334-6.

22. Zafar T, Brahmbhatt H, Imam G, ul Hassan S, Strathdee SA. HIV knowledge and risk behaviors among Pakistani and Afghani drug users in Quetta, Pakistan. J A cquir Immune Defic Syndr 2003;32(4):394-8.

23. Bertoni N, Singer M, Silva CM, Clair S, Malta $\mathrm{M}$, Bastos FI. Knowledge of AIDS and HIV transmission among drug users in Rio de Janeiro, Brazil. Harm Reduct J 2011;8:5.

24. Todd CS, Abed AM, Strathdee SA, Scott PT, Botros BA, Safi N, et al. Association between expatriation and HIV awareness and knowledge among injecting drug users in Kabul, Afghanistan: A cross-sectional comparison of former refugees to those remaining during conflict. Confl Health 2007;1:5.

25. Vian T, Semrau K, Hamer DH, Loan le TT, Sabin LL. HIV/AIDS-Related Knowledge and Behaviors Among Most-at-Risk Populations in Vietnam. Open AIDS J 2012;6:259-65.

26. Mondal NI, Hossain M, Rahman M. Knowledge and awareness about HIV/AIDS among garments workers in Gazipur District. Soc Sci 2008;3 (7):528-30.

27. Jahan M. Study on knowledge about Sexually Transmitted Diseases (STDs) among the garment workers of some selected garments factory in Dhaka city. Dhaka: NIPSOM, 2000. 